\title{
Oxidation of Intravenous Lipid in Infants and Children With Systemic Inflammatory Response Syndrome and Sepsis
}

\author{
ELENA CARESTA, AGOSTINO PIERRO, MOTI CHOWDHURY, MARK J. PETERS, MARCO PIASTRA, AND SIMON EATON
}

\author{
The Institute of Child Health and Great Ormond Street Hospital for Children NHS Trust [E.C., A.P., M.C., M.J.P., S.E.], University \\ College London, London, WC1N 1EH, UK; and Paediatric Intensive Care Unit [E.C., M.P.], Catholic University, O0168 Rome, Italy
}

\begin{abstract}
During sepsis in adults, fat becomes a preferred fuel; however, oxidation may be impaired relative to the circulating fatty acid levels. Little is known about the ability of infants and children to oxidize lipids during systemic inflammation (SIRS) and sepsis. The aim of this study was to examine the oxidation of exogenous lipid in these patients. Sixteen patients with SIRS/sepsis and eight controls with no evidence of sepsis were studied by indirect calorimetry during an i.v. lipid utilization test $(1 \mathrm{~h}$ of $0.3 \mathrm{~g} / \mathrm{kg} / \mathrm{h}$ glucose followed by $3 \mathrm{~h}$ of $0.1 \mathrm{~g} / \mathrm{kg} / \mathrm{h}$ glucose plus $0.15 \mathrm{~g} / \mathrm{kg} / \mathrm{h}$ lipid). The respiratory quotient (RQ) (1.0 for carbohydrate utilization and 0.7 for fat utilization) was measured. Results were compared by repeatedmeasures analysis of variance (ANOVA), paired or unpaired $t$ tests. There was no difference in baseline RQ between controls and patients with SIRS/sepsis (mean $\pm \mathrm{SD} ; 0.82 \pm 0.08$ versus $0.82 \pm 0.04$ ). The $\mathrm{RQ}$ of controls dropped significantly to $0.78 \pm 0.08$ at $240 \mathrm{~min}(p<$ $0.001)$. The RQ of patients with SIRS/sepsis also fell to $0.78 \pm 0.06$ $(p<0.01)$. Infants and children with SIRS/sepsis are able to oxidize i.v. lipid. (Pediatr Res 61: 228-232, 2007)
\end{abstract}

$\mathrm{O}$ ptimal nutrition of critically ill infants and children remains an unsolved problem, particularly during sepsis. During sepsis in adults, fat becomes a preferred fuel for oxidation $(1,2)$, which together with increased gluconeogenesis (3) can contribute to hyperglycemia (4). However, fat mobilization greatly exceeds oxidation under these conditions, resulting in considerable cycling $(5,6)$. This could be due to inhibition of lipoprotein lipase (7-9), an increase in very low density lipoprotein production (10), decreased low-density lipoprotein clearance (11), or decreased oxidation of fatty acids (12). Proinflammatory cytokines increase adipose tissue lipolysis (13) and hepatic triglyceride (TG) release (14) but can impair lipoprotein lipase activity (15) and fatty acid oxidation $(16,17)$. Thus, the overall effects of systemic inflammation and sepsis on oxidative metabolism of exogenous fat are difficult to predict. However, the fact that individual effects on different stages of fatty acid oxidation observed in clinical sepsis are similar to those exerted by proinflammatory cytokines suggests that the overall effects of SIRS and sepsis on lipid oxidation may well be similar.

There is little information on the ability of infants and children to oxidize fat during sepsis or critical illness. Some

Received May 23, 2006; accepted September 14, 2006.

Correspondence: Simon Eaton, Ph.D., Department of Paediatric Surgery, Institute of Child Health, 30, Guilford Street, London WC1N 1EH, UK; e-mail: s.eaton@ich. ucl.ac.uk

DOI: 10.1203/01.pdr.0000252441.91671.e5 authors have suggested that hypermetabolic critically ill infants preferentially oxidize fat (18), whereas in a study of infants and children with SIRS and sepsis, we could find no difference in the RQ between critically ill and control patients (19). Studies performed on septic premature neonates suggested impaired fat oxidation $(20,21)$.

Although lipids form an important component of parenteral nutrition, excess lipid administration can result in hypertriglyceridemia, impairment of leukocyte and platelet function, impaired pulmonary function, and other metabolic disturbances including an increase in serum free fatty acids. Studies in premature neonates have shown an increase in plasma TG levels during sepsis $(20,21)$. Lipid administration during total parenteral nutrition has been linked to an increase in lipid peroxidation and to how much lipid is used (22). Impairment of lipid oxidation during sepsis could also therefore contribute to free radical production. In addition, administration of lipid itself is a risk factor for infection (23). Hence, although not evidence based, most centers introduce lipid gradually with close monitoring of TG levels (24). Whether lipid provision needs to be altered during SIRS or sepsis in infants and children is unknown.

The aim of this study was to determine whether SIRS and sepsis affect oxidation of i.v. lipid in infants and children.

\section{METHODS}

Patients. Studies were performed in 16 critically ill patients with sepsis or SIRS requiring intensive care in Great Ormond Street Hospital for Children, London, UK, and Catholic University of Rome, Italy. SIRS was defined as the systemic inflammatory response to a variety of severe clinical insults and sepsis as the systemic response to a documented infection $(19,25)$ (Table 1). The diagnoses of the SIRS/sepsis patients are shown in Table 2; patients were studied within $36 \mathrm{~h}$ after admission. A control group of eight stable infants and children was also studied. Six of them were surgical patients studied $>48$ $\mathrm{h}$ after surgery; one patient had chronic colitis and one patient an intracranial hemorrhage. Patients with chronic lung disease or congenital metabolic abnormalities were excluded. All critically ill patients and four control patients were mechanically ventilated, and the remaining patients were spontaneously breathing without oxygen supplement.

Respiratory gas exchange measurement. Mechanically ventilated patients were enrolled in the study only if ventilated with Servo Ventilator (SV 300, SV 900, or Servo C; Siemens, Elema, Sweden) receiving $<50 \% \mathrm{O}_{2}$. Respiratory gas exchange was measured by an indirect calorimeter (Datex Deltratrac II, Helsinki, Finland) as previously described in ventilated infants (26)

Abbreviations: MDA, malondialdehyde; NEFAs, nonesterified fatty acids; REE, resting energy expenditure; SIRS, systemic inflammatory response syndrome; TG, triglyceride; $\mathbf{V C O}_{2}$, carbon dioxide production; $\mathbf{V O}_{2}$, oxygen consumption 
Table 1. Current definitions of SIRS/sepsis recommended for children

SIRS defined as two or more of the following:

Hyper- or hypothermia: $\mathrm{T} \geq 38^{\circ} \mathrm{C}$ or $<36^{\circ} \mathrm{C}$

Tachycardia: infant HR $>160 \mathrm{bpm}$; child HR $>150 \mathrm{bpm}$; adolescent HR $>90 \mathrm{bpm}$

Tachypnea: infant RR $>60$ bpm; child RR 50 bpm; adolescent RR $>20$ bpm Pathologic WBCs: $>15,000$ cells $/ \mu \mathrm{L},<4000$ cells $/ \mu \mathrm{L}$ or $>10 \%$ immature (band) forms

Sepsis: SIRS with proven infective cause; HR, heart rate; $T$, temperature; bpm, beats per minute; WBCs, white blood cells.

and children (19). Inspired and expired $\mathrm{O}_{2}$ and $\mathrm{CO}_{2}$ were analyzed to calculate the $\mathrm{RQ}\left(\mathrm{RQ}=\mathrm{VCO}_{2} / \mathrm{VO}_{2}\right)$ (carbon dioxide production/oxygen consumption) (27). The RQ is influenced by the type of substrate used with an RQ approaching 0.7 for fat oxidation, an RQ of 1.0 for glucose oxidation, and an $\mathrm{RQ}>1.0$ for lipogenesis (28). We did not examine urinary nitrogen excretion as we assumed that the component of the RQ due to protein oxidation would not change during the study (i.e. glucose and fat infusion). This assumption is supported by studies indicating no effect of glucose or fat intake on protein metabolism $(29,30)$. We have previously validated RQ measurements in both modes using this indirect calorimeter, and the error in the RQ less than $\pm 3 \%(19,31)$.

Intravenous fat utilization test. During $4 \mathrm{~h}$ of indirect calorimetry, while other nutrition was discontinued, the capacity to oxidize fat was tested using an i.v. fat utilization test previously described in infants (32). During the first hour, patients received $0.3 \mathrm{~g} / \mathrm{kg} / \mathrm{h}$ glucose. During the following $3 \mathrm{~h}$, the glucose infusion was decreased to $0.1 \mathrm{~g} / \mathrm{kg} / \mathrm{h}$ (to avoid hypoglycemia) and i.v. fat (Intralipid 30\%; Pharmacia \& Upjohn, Milton Keynes, Bucks, UK) at 0.15 $\mathrm{g} / \mathrm{kg} / \mathrm{h}$, well below the recommended dose in infants and children and one sixth of the daily dose usually given in our hospital during i.v. feeding. RQ values were averaged over $30 \mathrm{~min}$, excluding periods of crying or movement. Blood samples (ethylenediamine tetraacetic acid tubes) for measurement of plasma MDA, TG, and nonesterified fatty acids (NEFAs) were taken at the beginning and the end of the protocol, where an arterial or venous line was available and therefore no additional venipuncture was required, as this was a requirement of our ethical approval.

Plasma samples. Plasma malondialdehyde (MDA), a measure of lipid peroxidation, was measured by high-performance liquid chromatography (33). Plasma TGs were measured spectrophotometrically (Sigma Chemical Co.) and nonesterified fatty acids (NEFAs) were measured by a spectrophotometric kit (Wako Chemical Company).

Statistical evaluations. Data were normally distributed and are expressed as mean $\pm \mathrm{SD}$. Comparisons were made using a $t$ test for comparisons between groups and by repeated-measures ANOVA to analyze the drop in the RQ over time. Instat v3.0 was used for comparisons.

The study protocol was approved by the Great Ormond Street Hospital for Children and Institute of Child Health Research Ethics Committee. Informed parental consent was obtained for each patient.

\section{RESULTS}

Patient demographics. Patients with SIRS/sepsis $(n=16)$ were of a median age of 21.8 (range, 3.3-202) months, which was similar to the age of controls [20.7 (range, 0.3-96) months; $n=8$ ] at the time of study.
Intravenous fat utilization test. The baseline RQ was $0.82 \pm$ 0.08 in control patients $(n=8)$. As expected, there was a significant drop in the RQ after lipid infusion was initiated, reflecting a switch from carbohydrate to fat oxidation (Fig. $1 A)$. The RQ was significantly lower compared with baseline at 180,210 , and $240 \min ($ all $p<0.001)$. The baseline RQ was $0.82 \pm 0.04$ in patients with SIRS or sepsis $(n=16)$, and there was similarly a significant drop in the RQ in these patients (Fig. $1 B$ ), such that the RQ was significantly lower than baseline at 210 and $240 \mathrm{~min}(p<0.01)$. There was no significant difference in the RQ at any time between the control and SIRS/sepsis patients.

TG and nonesterified fatty acid analysis. Blood samples were available from four of eight control patients and 12 of 16 SIRS/sepsis patients. Plasma TG levels before lipid infusion were significantly higher $(1.35 \pm 0.64 \mathrm{mmol} / \mathrm{L})$ in SIRS/ sepsis patients than in controls $(0.91 \pm 0.25 \mathrm{mmol} / \mathrm{L}, p=$ $0.03)$. Lipid infusion would be expected to increase plasma TG levels. This was indeed shown to be the case; in all patients, there was a significant increase in plasma TGs after Intralipid infusion compared with before lipid infusion. This increase took place in both SIRS and sepsis patients (Fig. 2B, preIntralipid, $1.35 \pm 0.57 \mathrm{mmol} / \mathrm{L}$, postinfusion $2.09 \pm 0.82$, $p<0.0001$ on paired $t$ test) and controls (Fig. 2A), although samples were only available in four control patients so statistical evaluation was not possible.

Action of lipoprotein lipase on plasma TGs makes NEFAs available for tissue uptake. Lipid infusion would therefore be expected to increase NEFA levels, provided lipoprotein lipase is not inhibited. NEFA levels before lipid infusion were greater in SIRS/sepsis patients $(0.70 \pm 0.37 \mathrm{mmol} / \mathrm{L})$ than in controls $(0.19 \pm 0.08 \mathrm{mmol} / \mathrm{L})$. The NEFA levels in most patients, both controls and SIRS/sepsis patients, increased in response to lipid infusion (Fig. $2 C, D$ ).

There is normally a positive linear relationship between circulating TGs and NEFAs. We therefore analyzed whether such a relationship persisted in SIRS/septic patients. There was a strong correlation between TGs and NEFAs in control patients $\left(r^{2}=0.71, p=0.009\right)$ but not in SIRS/sepsis patients considered as a whole group $\left(r^{2}=0.09, p=\right.$ not significant $)$ (Fig. 3).

Lipid peroxidation in plasma. As lipid peroxidation occurs during parenteral nutrition (34) and has specifically been linked to the amount of infused and oxidized fat $(22,35)$, we wanted to determine whether short-term lipid infusion at a

Table 2. Clinical diagnoses of patients with systemic inflammatory response syndrome and sepsis

\begin{tabular}{lcrrr}
\hline & No. of patients & Intubation status & PRISM score & Positive blood culture \\
\hline Meningococcal septicemia & 4 & $4 / 4$ & $10,15,16,20$ & 16,23 \\
Streptococcus A sepsis & 2 & $2 / 2$ & 20 & 23 \\
Pneumococcal sepsis & 1 & $1 / 1$ & $3 / 2$ & $1 / 1$ \\
Pneumococcal meningitis & 1 & $1 / 1$ & 36 & $1 / 1$ \\
Septic shock & 1 & $1 / 1$ & $12,15,17,18$ & 10 \\
Pneumonia & 4 & $4 / 4$ & 20 & $0 / 1$ \\
Behçet syndrome with respiratory failure & 1 & $1 / 1$ & $0 / 1$ \\
Bronchiolitis with suspected infection & 1 & $1 / 1$ & 23 & $0 / 1$ \\
Postoperative SIRS & 1 & $1 / 1$ & $0 / 1$ \\
\hline
\end{tabular}


A - control

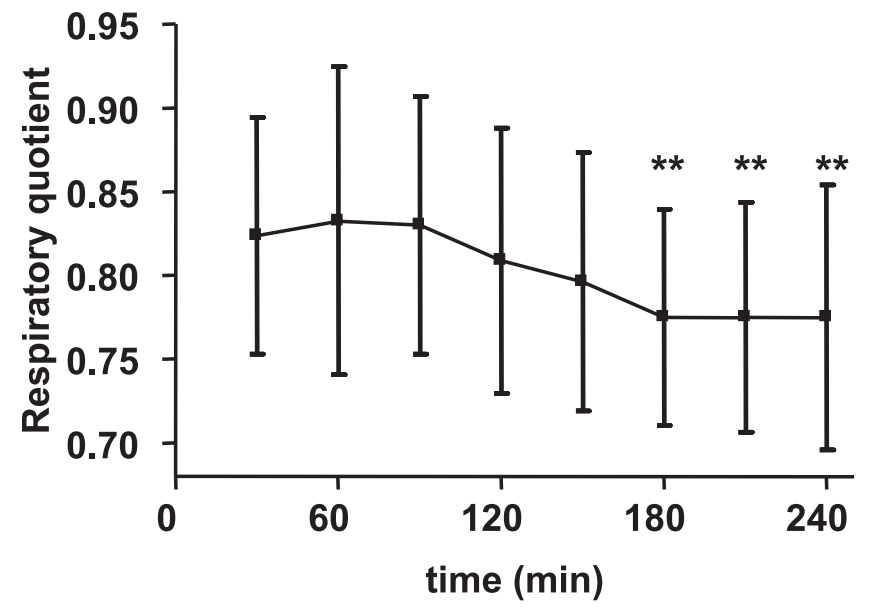

B - SIRS/sepsis

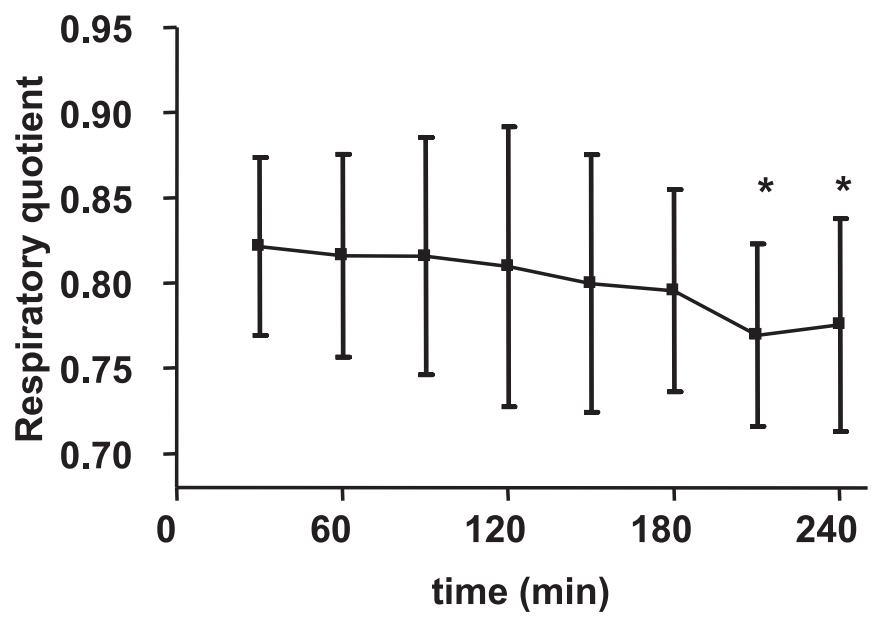

Figure 1. Changes in the RQ over time in control patients $(n=8)(A)$ and patients with SIRS or sepsis $(n=16)(B)$. Results were compared with baseline (30-min time point) by repeated-measures ANOVA. $* p<0.01 \mathrm{vs}$ baseline; $* * p<0.001 v s$ baseline.

relatively high infusion rate led to an increase in lipid peroxidation. Measurement of plasma malondialdehyde (MDA) as a marker of lipid peroxidation indicated that lipid infusion over $3 \mathrm{~h}$ did not lead to an increase in lipid peroxidation; there was no significant difference in plasma MDA between pre- and post-lipid infusion samples in SIRS/sepsis patients $(p=0.88)$ or in controls (Fig. $4 A, B$ ).

\section{DISCUSSION}

Malnutrition is common in critically ill children and is associated with increased physiologic instability and increased quantity of care (36). The common belief that critically ill children would be hypermetabolic has not been confirmed $(19,37)$; on the contrary, they are more frequently hypometabolic (38). The patterns of energy expenditure, the nature of fuel utilization, and whether manipulation of these or other factors can affect patient outcome represent an important research field.

Several tests have been used to estimate ability to tolerate or metabolize i.v. lipid. Many of these examine plasma lipid

\section{A - control}

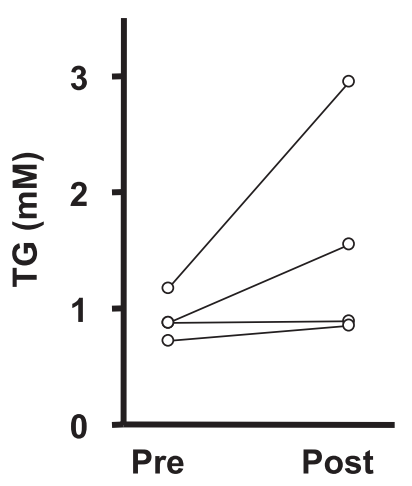

C - control

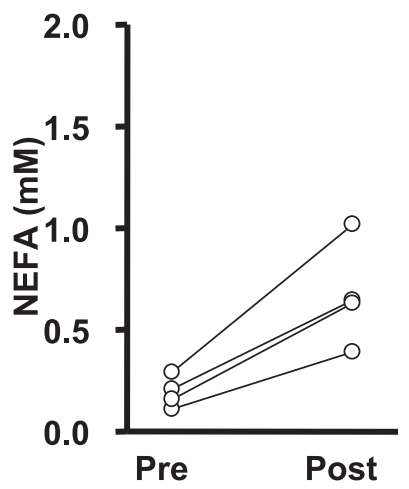

B - SIRS/sepsis

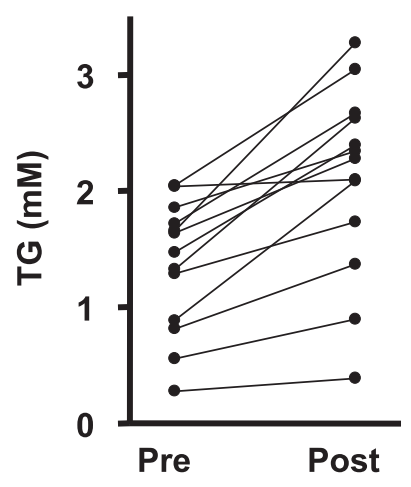

D - SIRS/sepsis

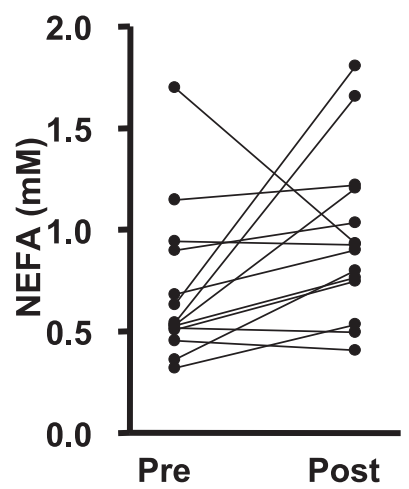

Figure 2. Plasma triglyceride $(A, B)$ and $\operatorname{NEFA}(C, D)$ concentration in patients before and after lipid infusion in control patients $(n=4)(A, C)$ and patients with SIRS/sepsis $(n=13)(B, D)$.

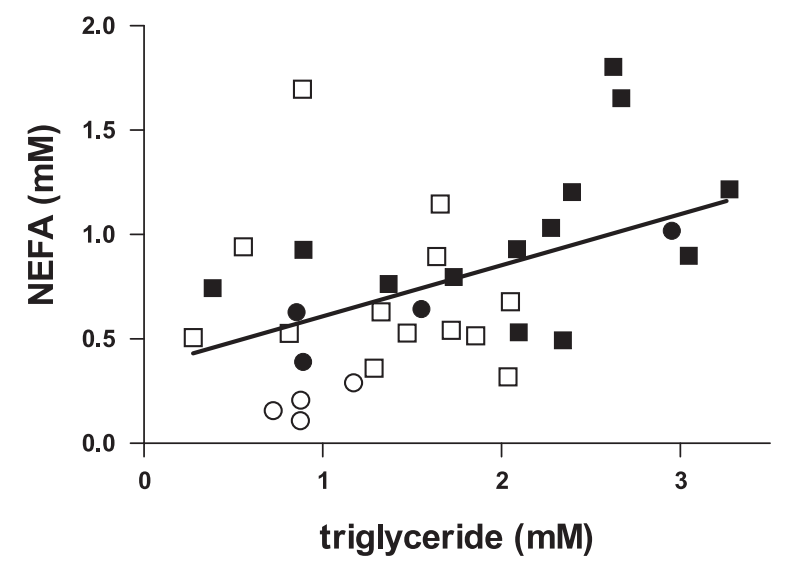

Figure 3. Relationship between NEFA and TG concentrations in control patients (circles, $n=3-4$ ) and SIRS/sepsis patients (squares, $n=13$ ). Open symbols, before lipid infusion; closed symbols, after lipid infusion. The linear regression line refers to all patients. $r^{2}=0.21, p=0.006$.

clearance $(39,40)$, but this does not reflect oxidation (41). Oxidation of i.v. lipid can be followed by oxidation of isotopically labeled lipid to $\mathrm{CO}_{2}$ (41). However, for such tests to be clinically relevant, they require isotopically labeled lipid emulsions otherwise identical to those used clinically, and these are not available. The indirect calorimetry i.v. fat utilization test (32) relies on the fact that fat has an RQ of 0.7, whereas carbohydrate has an RQ of 1.0. A baseline RQ is measured in the absence of exogenous lipid, lipid infusion is 
A - control

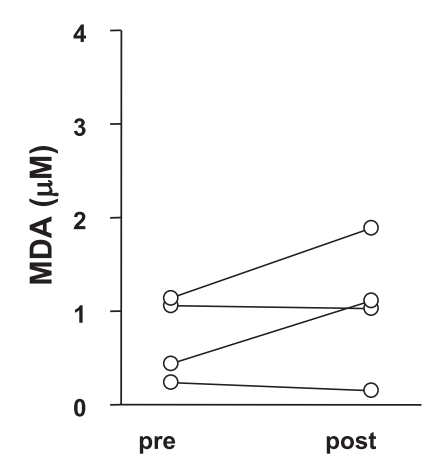

B - SIRS/sepsis

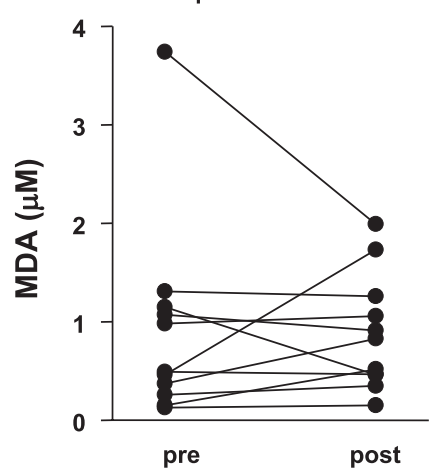

Figure 4. Plasma MDA before and after lipid infusion in control patients $(n=4)(A)$ and patients with SIRS/sepsis $(n=12)(B)$.

initiated, and if fat is oxidized, a drop in RQ is observed. Although this test has the advantages that it measures oxidation of a clinically relevant lipid emulsion, it does have some limitations: First, as with any indirect calorimetry-based method, only net effects are observed. However, it is unlikely that significant lipogenesis occurred during our study, as glucose administration was low. Measurement of $\mathrm{VCO}_{2}$ by indirect calorimetry assumes that the bicarbonate pool is constant and so should be performed under steady-state conditions. Alteration of substrate oxidation will alter the metabolic $\mathrm{VCO}_{2}$ rate and therefore the size and kinetics of the bicarbonate pool. Hence, there is a delay before breath $\mathrm{CO}_{2}$ reflects changes in metabolism, and in the lipid utilization test, time must be allowed to reach a new steady state, which was achieved in both control and SIRS/sepsis patients in our study. The lag time before a fall in the RQ is observed therefore reflects the time to initiate lipid oxidation plus time to reequilibrate the bicarbonate pool. Although both spontaneously breathing and ventilated patients were included in the control group, the aim of this study was to evaluate the ability of patients to decrease their RQ in response to fat infusion rather than to compare absolute values of the RQ or REE between the groups. As described in the Materials and Methods section, measurement of the RQ has been validated in each measurement mode.

In the current study, we have shown that infants and children with SIRS or sepsis were able to oxidize i.v. lipid, as shown by a drop in the RQ similar to that in controls. Lipid peroxidation has been reported to be associated with fat infusion in infancy (42), and it is possible that lipid infusion therefore exposes the infant to free radical stress. However, we have previously shown that, provided carbohydrate infusion is limited, lipid is oxidized for fuel rather than peroxidized (22), so our finding that MDA production was not altered by lipid infusion is consistent with lipid oxidation. Although the SIRS/sepsis patients whom we studied were able to oxidize fat, this could be related to the timing of the study - patients were studied early in their intensive care unit admission, and impairment in fat oxidation could be acquired later. Although only a few patients were studied in the control group, the use of repeated-measures ANOVA meant that each patient was effectively acting as his or her own control, and thus this enabled us to detect a significant drop in the RQ. Unfortunately, blood samples were only available from a few patients in the control group for ethical reasons.

Interestingly, four of the patients in the SIRS/sepsis group had meningococcal septicemia, and a separate analysis of these patients suggests that were not able to decrease their RQ in response to lipid infusion, and their plasma NEFA levels did not decrease (results not shown). This suggests that patients with meningococcal septicemia may not be able to oxidize lipids, possibly due to inhibition at the level of lipoprotein lipase, but this needs verification in a larger number of patients.

Patients with SIRS/sepsis were able to oxidize $0.15 \mathrm{~g} / \mathrm{kg} / \mathrm{h}$ of lipid, which would correspond to $3.6 \mathrm{~g} / \mathrm{kg}$ if lipid infusion was continued for $24 \mathrm{~h}$. This suggests that despite the caution shown by many centers in administering lipids to septic infants and children, most are able to oxidize considerable amounts of lipid. There may be advantages to maintaining lipid infusion in SIRS/sepsis, as decreasing metabolic $\mathrm{VCO}_{2}$ could decrease respiratory load. In the present study, we infused lipid at a relatively high rate, with a low rate of glucose administration. It is likely that lower amounts of lipid would also be adequately oxidized provided that carbohydrate administration is not excessive. Another note of caution is that even in the absence of exogenous lipid, the baseline TG levels of SIRS/sepsis patients was significantly higher than those of controls. Monitoring of TGs during lipid infusion in patients with SIRS/sepsis is probably even more important than in other infants and children. Because of the short-term nature of the test used, we are only able to measure the ability of infants and children to oxidize lipid when challenged with a sudden increase. Adaptation may well take place when lipids are administered for longer, but lipid administration over a longer period could conversely potentially lead to lipid intolerance.

In this study, we examined only oxidation of i.v. lipid rather than utilization for other purposes. Lipid storage or utilization in other metabolic pathways could be impaired in septic infants and children, but this would best be measured by stable isotopic methods. Another shortcoming of our study is the large interpatient variability; we tried to overcome this by using paired statistics (i.e. repeated-measures ANOVA or paired $t$ tests). There could, however, be other important differences, for example, differing responses according to age, which would become apparent if more patients were studied from matched groups.

In conclusion, we have demonstrated that infants and children with SIRS and sepsis are able to oxidize exogenous lipid at clinically relevant infusion rates.

\section{REFERENCES}

1. Samra JS, Summers LK, Frayn KN 1996 Sepsis and fat metabolism. Br J Surg 83:1186-1196

2. Eaton S, Pierro A 2005 Carnitine and fatty acid oxidation in sepsis. Chem Monthly 136:1483-1492

3. Wolfe RR 1997 Substrate utilization insulin resistance in sepsis/trauma. Baillieres Clin Endocrinol Metab 11:645-657

4. Mizock BA 2001 Alterations in fuel metabolism in critical illness: hyperglycaemia Best Pract Res Clin Endocrinol Metab 15:533-551

5. Nordenstrom J, Carpentier YA, Askanazi J, Robin AP, Elwyn DH, Hensle TW, Kinney JM 1983 Free fatty-acid mobilization and oxidation during total parenteralnutrition in trauma and infection. Ann Surg 198:725-735 
6. Wolfe RR, Martini WZ 2000 Changes in intermediary metabolism in severe surgical illness. World J Surg 24:639-647

7. Robin AP, Askanazi J, Greenwood MR, Carpentier YA, Gump FE, Kinney JM 1981 Lipoprotein-lipase activity in surgical patients - influence of trauma and infection. Surgery 90:401-408

8. Picard F, Kapur S, Perreault M, Marette A, Deshaies Y 2001 Nitric oxide mediates endotoxin-induced hypertriglyceridemia through its action on skeletal muscle lipoprotein lipase. FASEB J 15:1828-1830

9. Lanza-Jacoby S, Sedkova N, Phetteplace H, Perrotti D 1997 Sepsis-induced regulation of lipoprotein lipase expression in rat adipose tissue and soleus muscle. J Lipid Res 38:701-710

10. Wolfe RR, Shaw JH, Durkot MJ 1985 Effect of sepsis on VLDL kinetics - responses in basal state and during glucose-infusion. Am J Physiol 248:E732-E740

11. Liao W, Rudling M, Angelin B 1996 Endotoxin suppresses rat hepatic low-density lipoprotein receptor expression. Biochem J 313:873-878

12. Memon RA, Fuller J, Moser AH, Smith PJ, Feingold KR, Grunfeld C 1998 In vivo regulation of acyl-CoA synthetase mRNA and activity by endotoxin and cytokines. Am J Physiol 275:E64-E72

13. Stouthard JM, Romijn JA, Van der Poll T, Endert E, Klein S, Bakker PJ, Veenhof $\mathrm{CH}$, Sauerwein HP 1995 Endocrinologic and metabolic effects of Interleukin-6 in humans. Am J Physiol Endocrinol Metab 31:E813-E819

14. Starnes HF, Warren RS, Jeevanandam M, Gabrilove JL, Larchian W, Oettgen HF, Brennan MF 1988 Tumor necrosis factor and the acute metabolic response to tissue-injury in man. J Clin Invest 82:1321-1325

15. Fried SK, Zechner R 1989 Cachectin/tumor necrosis factor decreases human adipose tissue lipoprotein lipase mRNA levels, synthesis, and activity. J Lipid Res 30:19171923

16. Memon RA, Feingold KR, Moser AH, Doerrler W, Adi S, Dinarello CA, Grunfeld C 1992 Differential effects of interleukin-1 and tumor necrosis factor on ketogenesis. Am J Physiol 263:E301-E309

17. Nachiappan V, Curtiss D, Corkey BE, Kilpatrick L 1994 Cytokines inhibit fatty-acid oxidation in isolated rat hepatocytes-synergy among the TNF, IL-6, and IL-1. Shock 1:123-129

18. Coss-Bu JA, Klish WJ, Walding D, Stein F, Smith EO, Jefferson LS 2001 Energy metabolism, nitrogen balance, and substrate utilization in critically ill children. Am J Clin Nutr 74:664-669

19. Turi RA, Petros A, Eaton S, Fasoli L, Powis M, Basu R, Pierro A 2001 Energy metabolism of infants and children with systemic inflammatory response syndrome and sepsis. Ann Surg 233:581-587

20. Park W, Paust H, Schroder H 1984 Lipid infusion in premature infants suffering from sepsis. JPEN J Parenter Enteral Nutr 8:290-292

21. Park W, Paust H, Brosicke H, Knoblach G, Helge H 1986 Impaired fat utilization in parenterally fed low-birth-weight infants suffering from sepsis. JPEN J Parenter Enteral Nutr 10:627-630

22. Basu R, Muller DP, Eaton S, Merryweather I, Pierro A 1999 Lipid peroxidation can be reduced in infants on total parenteral nutrition by promoting fat utilisation. J Pediatr Surg 34:255-259

23. Freeman J, Goldmann DA, Smith NE, Sidebottom DG, Epstein MF, Platt R 1990 Association of intravenous lipid emulsion and coagulase-negative staphylococcal bacteremia in neonatal intensive-care units. N Engl J Med 323:301-308

24. Agus MS, Jaksic T 2002 Nutritional support of the critically ill child. Curr Opin Pediatr 14:470-481
25. American College of Chest Physicians/Society of Critical Care Medicine Consensus Conference Committee 1992 ACCP/SCCM Consensus Conference: definition for sepsis and organ failure and guidelines for the use of innovative therapies in sepsis. Crit Care Med 20:864-874

26. Powis MR, Smith K, Rennie M, Halliday D, Pierro A 1998 Effect of major abdominal operations on energy and protein metabolism in infants and children. J Pediatr Surg 33:49-53

27. Jones MO, Pierro A, Hammond P, Nunn A, Lloyd DA 1993 Glucose utilization in the surgical newborn infant receiving total parenteral nutrition. J Pediatr Surg 28:1121-1125

28. Livesey G, Elia M 1988 Estimation of energy expenditure, net carbohydrate utilization, and net fat oxidation and synthesis by indirect calorimetry: evaluation of errors with special reference to the detailed composition of fuels. Am J Clin Nutr 47:608-628

29. Jones MO, Pierro A, Garlick PJ, McNurlan MA, Donnell SC, Lloyd DA 1995 Protein metabolism kinetics in neonates: effect of intravenous carbohydrate and fat. J Pediatr Surg 30:458-462

30. Pierro A, Jones MO, Garlick PJ, McNurlan MA, Donnell SC, Lloyd DA 1995 Non-protein energy intake during total parenteral nutrition: effect on protein turnover and energy metabolism. Clin Nutr 14:47-49

31. Powis MR, Smith K, Rennie M, Halliday D, Pierro A 1999 Characteristics of protein and energy metabolism in neonates with necrotizing enterocolitis-a pilot study. J Pediatr Surg 34:5-10

32. Pierro A, Carnielli V, Filler RM, Smith J, Heim T 1989 Metabolism of intravenous fat emulsion in the surgical newborn. J Pediatr Surg 24:95-101

33. Stefanutti G, Pierro A, Vinardi S, Spitz L, Eaton S 2005 Moderate hypothermia protects against systemic oxidative stress in intestinal ischemia and reperfusion injury. Shock 24:159-164

34. Basu R, Muller DP, Papp E, Merryweather I, Eaton S, Klein N, Pierro A 1999 Free radical formation in infants: the effect of critical illness, parenteral nutrition, and enteral feeding. J Pediatr Surg 34:1091-1095

35. Pitkanen O, Hallman M, Andersson S 1991 Generation of free-radicals in lipid emulsion used in parenteral-nutrition. Pediatr Res 29:56-59

36. Pollack MM, Ruttimann VE, Wiley JS 1985 Nutritional depletions in critically ill children: associations with physiologic instability and increased quantity of care. JPEN J Parenter Enteral Nutr 9:309-319

37. Taylor RM, Cheeseman P, Preedy VR, Baker AJ, Grimble GK 2003 Can energy expenditure be predicted in critically ill children? Pediatr Crit Care Med 4: $176-180$

38. Vazquez-Martinez JL, Martinez-Romillo PD, Sebastian JD, Tarrio FR 2004 Predicted versus measured energy expenditure by continuous, online indirect calorimetry in ventilated, critically ill children during the early postinjury period. Pediatr Crit Care Med 5:19-27

39. Carlson LA, Rossner S 1972 Methodological study of an intravenous fat tolerancetest with Intralipid R emulsion. Scand J Clin Lab Invest 29:271-280

40. Thorne A, Aberg W, Carneheim C, Olivecrona T, Nordenstrom J 2005 Influence of trauma on plasma elimination of exogenous fat and on lipoprotein lipase activity and mass. Clin Nutr 24:66-74

41. Nordenstrom J, Carpentier YA, Askanazi J, Robin AP, Elwyn DH, Hensle TW, Kinney JM 1982 Metabolic utilization of intravenous fat emulsion during total parenteral nutrition. Ann Surg 196:221-231

42. Wispe JR, Bell EF, Roberts RJ 1985 Assessment of lipid peroxidation in newborn infants and rabbits by measurements of expired ethane and pentane: influence of parenteral lipid infusion. Pediatr Res 19:374-379 